Paper presented at NATO Advanced Study Institute: Coping with Flash Floods

Ravello, Italy, 8-17 November, 1999

\title{
REVELATIONS FROM 21 YEARS OF PROVIDING FLASH FLOOD WARNING SUPPORT IN DENVER, COLORADO
}

\author{
KEVIN G. STEWART \\ National Hydrologic Warning Council \\ Urban Drainage and Flood Control District \\ Denver, Colorado 80211 USA
}

\section{Introduction}

This paper presents an operational perspective on the effectiveness of local flood warning programs in the urban areas and mountain regions surrounding Denver, Colorado. Many lessons have been learned during the program's 21-year history by building close working relationships with public and private weather forecast services; local emergency managers; public works and engineering departments; emergency response agencies; elected officials; researchers; and the local news media.

Denver's program began with findings and recommendations from behavioral science research following the 1976 Big Thompson Canyon flash flood [2,4]. With this advice in hand in 1977, steps were immediately taken by the Urban Drainage and Flood Control District with their local government partners to develop automated flood detection capabilities, a basin-specific flood warning plan, communication procedures, threat evaluation methods, and a step-by-step warning decision process for Boulder Creek. An integral part of this local flood warning program was the establishment of a flood prediction and early notification component, utilizing the services of a private meteorologist to supplement warnings and forecasts provided by the National Weather Service (NWS). The District also recognized the potential for this specialized flood forecasting service to benefit areas other than Boulder Creek. Thus, in 1979 the Flash Flood Prediction Program (F2P2) was born, serving the entire District including Denver and portions of the five surrounding counties of Adams, Arapahoe, Boulder, Douglas and Jefferson.

Automated flood detection technology available in the late 1970s enabled the District to take the actions it did, empowering local officials to make informed early warning decisions with confidence. No longer would emergency managers rely exclusively on NWS flash flood warnings before taking protective actions. To emphasize the important role technology has played in this process, an historical perspective is presented to illustrate how some other U.S. flood disasters helped drive the development of affordable flood detection technology in the years preceding and following Big Thompson. The early formation of user groups and the contributions they have made toward bettering flood warning technologies and practices are also noted.

\section{Background}

For a number of years in the late 1960s and early 1970s, a small group of river forecasters in California were investigating ways to improve their ability to recognize flood threats. Frustrated by the lack of adequate precipitation data for estimating runoff and forecasting flood peaks, these individuals felt strongly that something had to be done to enhance or replace existing hydrologic data collection techniques. Available technologies either lacked real-time capabilities or were too costly; and those involved with the investigation had no funding from their respective agencies to pursue such endeavors [1]. It is interesting to note that at this time in history the United States was recovering from the wide-spread 1965 floods, which brought the National Flood Insurance Program into existence and in Colorado, the formation of the Urban Drainage and Flood Control District (UDFCD).

In June of 1972, a devastating flash flood killed 237 people and destroyed a large portion of Rapid City, South Dakota. This was one of the landmark events that preceded the Flood Disaster Protection Act becoming 
federal law in 1973. The Rapid City flash flood has also been pointed to as "the event" that sparked the initial prototype development of what is known today as ALERT (Automated Local Evaluation in Real-Time) equipment. First tested in 1974 on the American River in California, this "new technology" was designed to encourage high flood risk communities to install "low cost" equipment and develop their own local flood warning programs. This objective was realized in 1977 following a large forest fire in Monterey County, California, which caused fears regarding the increased flood potential there and in other parts of the State. Once again, a disaster provided the incentive for elected officials to take action by appropriating public funds for installing automated flood detection equipment. Many local governments throughout the United States have since become vested in using this and other flood detection technologies.

In Colorado the incentive was provided by the 1976 Big Thompson Canyon flash flood that claimed 145 lives. Just $50 \mathrm{~km}$ to the south, Boulder Creek had long been considered the state's most dangerous flash flood stream. Local officials in Boulder began asking questions like-what would happen if a similar storm occurs over Boulder Creek? Researchers at the University of Colorado were asked to answer this and other questions by studying what people did during the Big Thompson flood and estimating the potential benefits of implementing a local program to provide early flood detection and warning for the City of Boulder and other Front Range communities [3]. By January, 1978 an agreement was signed between the City of Boulder, Boulder County and the Urban Drainage and Flood Control District to design and install an automated flood detection network for Boulder Creek comprised of approximately 20 real-time self-reporting rain and stream gauges. A comprehensive flood warning plan was also developed for Boulder Creek incorporating early detection and notification into a warning decision process, and committing local officials to long term maintenance through annual plan updates and exercises.

\section{Early ALERT Systems}

The initial design of ALERT systems resulted directly from experience with other automated hydrologic data systems, which spanned nearly half a century. The components and techniques involved with implementing early systems focused on obtaining a continuously current database from a network of remotely located hydrologic sensors, with the primary objective being to maximize the time for quantitative evaluation of flood threats [1]. Today the goal remains essentially the same but the design focus has shifted toward developing more efficient methods of evaluating and recognizing flash flood potentials, including a better understanding of the atmospheric precursors to heavy precipitation.

Establishing reliable communication links had always been one of the greatest obstacles to acquiring realtime hydrologic information. The original engineering of ALERT radios and data transmission protocols resulted in a robust design that is still in use today.

ALERT data were first obtained using tape readout devices and subsequent evaluation procedures were, for the most part, manual. When the first microcomputers came on the scene, the natural fit for ALERT was immediately realized and business of data collection, display, analysis and remote access soon changed. These early desktops, however, were not very reliable and became obsolete after IBM ${ }^{\mathrm{TM}}$ introduced their Personal Computer. ALERT software developers soon selected a reliable operating system and designed a database that made efficient use of IBM's hardware. Since then, ALERT systems have kept pace with rapid technological changes in computers and data communications. Figure 1 shows some typical base station equipment in use between the 1974 and 1985 .
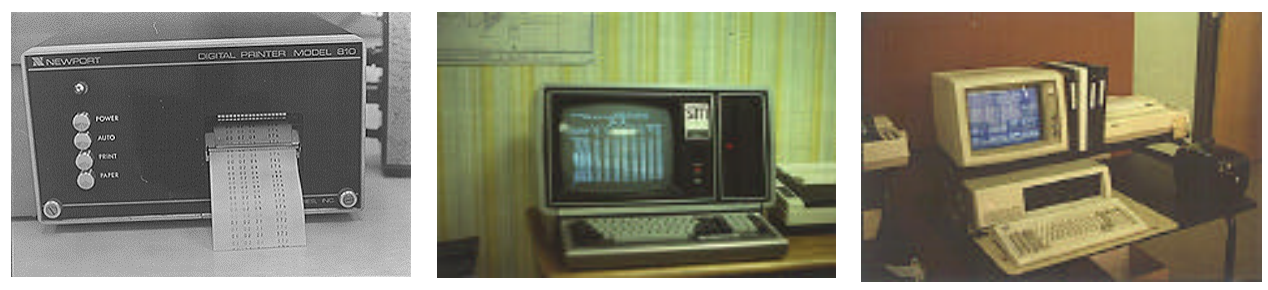

Figure 1. ALERT Base Station Evolution 


\section{The Denver/Boulder Area ALERT System}

The ALERT system in the Denver/Boulder, Colorado area is a major asset of the District's local flood warning program. It has experienced remarkable growth and utility over the past two decades. The flood detection network (FDN) now comprises 144 automated gauging stations with 266 instruments that provide continuous real-time measurements of rainfall, water levels, wind, temperature, relative humidity, barometric pressure and other parameters (Figure 2).

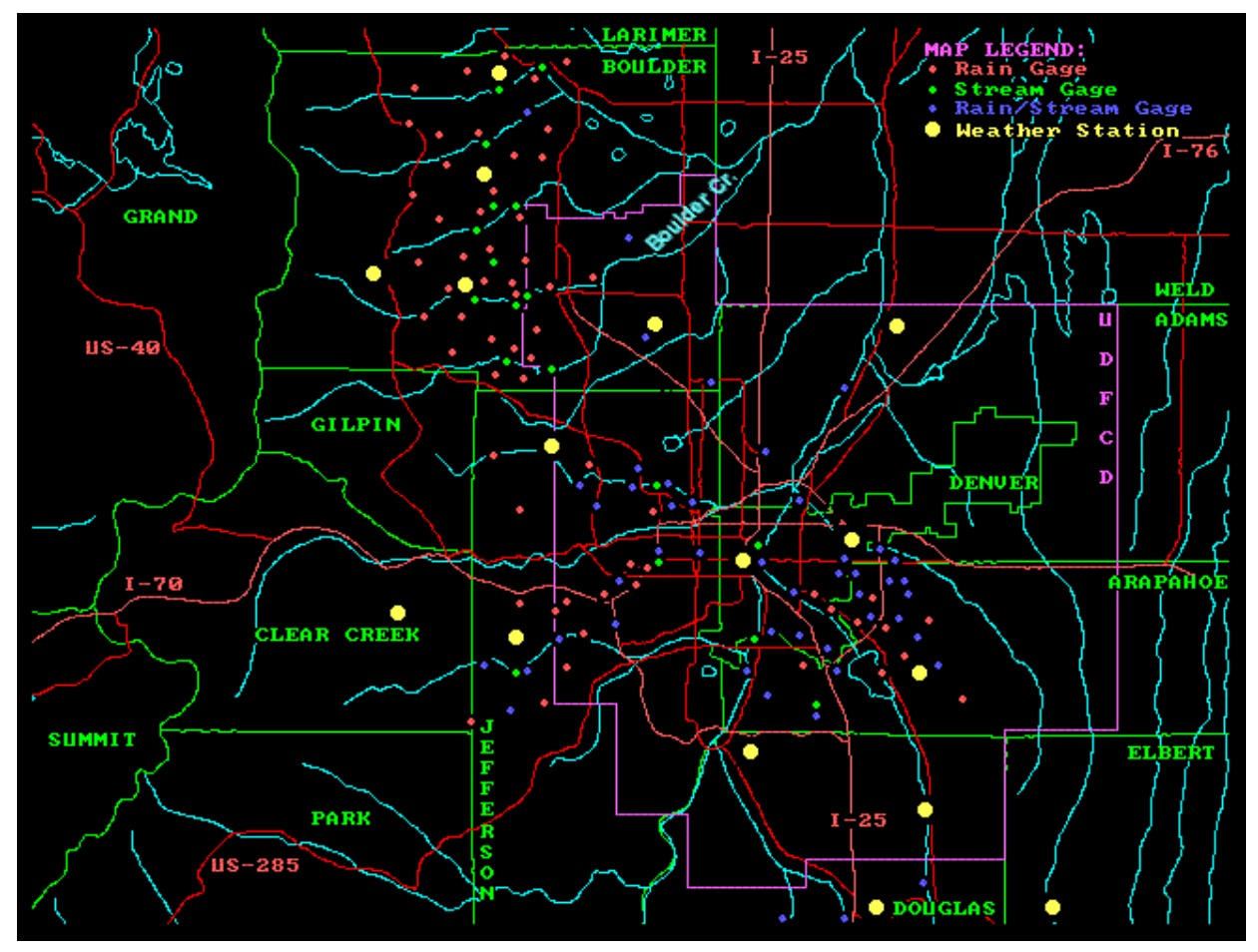

Figure 2. Denver, Colorado Regional ALERT System

The Boulder Creek FDN was initially operated and maintained by the Boulder County Sheriff's Department. Through its first decade of operation, Sheriff's Department officials were the principle users of the data and remote access capabilities were limited. Only a few external users had access to this system. Even the local NWS Forecast Office did not have access. This situation changed dramatically after the IBM PC-XT became the preferred base station platform.

The FDN measures precipitation using standard 1 mm ALERT tipping buckets. The water is collected atop a $3 \mathrm{~m}$ aluminum standpipe tower by a $305 \mathrm{~mm}$ diameter funnel. Data reports are event-driven and communicated via one-way FM radios to central base station receivers. With the "event" defined by a single bucket tip, base station operators have data immediately available for display and evaluation. The rain gauges in the District's FDN are not designed to measure frozen precipitation, while systems elsewhere do have this capability.

Stream gauges relay data in a similar manner and typically share the same electronics package with a rain gauge. The resolution for a water level change "event" is user-defined and varies depending on the electronics package and sensor dampening capabilities. The selected sample time interval and water level change for generating a report take into account the hydraulic sensitivity of the site, with the goal being to minimize the number of transmissions without sacrificing resolution. The submersible pressure transducer is the principal stream gauge device used by the District. A few stations use digital shaft encoders attached to standard float gauges in stilling wells. ALERT technology offers many other device options.

All weather stations measure rainfall, air temperature, relative humidity and wind speed/direction. Some stations measure barometric pressure. Special sensors have also been added to stations for non-flood purposes 
such as solar radiation, and fuel moisture and temperature for fire weather applications. With the exception of wind run and rain measurements, all ALERT weather stations are set to sample conditions every 15 minutes and transmit data when conditions change. By using this type of logic for weather stations and stream gauges, the amount of radio traffic is minimized while maintaining adequate temporal resolution. The large dots in Figure 2 designate weather stations. The importance of the ALERT Mesonet (meso-scale network of automated weather stations) for flash flood prediction is addressed later in this paper.

The District currently supports seven base stations in the Denver area with the primary base station located at the District's office. Each base station functions independently and has the ability to communication with other base stations in the system. Emergency generator power is available at some locations and all base stations are equipped with UPS battery backups. This high level of redundancy provides a fault tolerant environment relative to base station operations.

\subsection{SYSTEM MAINTENANCE}

The importance of data archiving and routine system maintenance became clear after the first few years of operation. Prior to 1986, data archiving was not considered a priority and the electronic methods available were not simple to use or very reliable. The early records from the Boulder FDN dating back to 1978 are essentially non-existent. Emphasis at that time was placed on the availability of real-time data for emergency decisionmaking, not data archiving. Routine field maintenance of gauges and other electronic parts was another early weakness that was identified and remedied in the mid-1980s. Considerable progress is made each year in this area by adhering to a strict maintenance schedule.

\subsubsection{Equipment Maintenance}

The District employs private sector businesses to maintain, repair and replace all electronic parts, communications equipment, mechanical components and hardware associated with the ALERT system. Detailed written records of all work activities are meticulously kept. The maintenance agreement specifies the schedule and requirements for conducting routine maintenance and unscheduled service calls when equipment fails. Supplemental provisions are incorporated in the contract for installing new stations and assisting the District with securing necessary radio licenses. The importance of good field maintenance cannot be overemphasized. Before public funds are spent to install automated gauging networks like ALERT, a commitment to annual maintenance should be made and associated costs identified.

\subsubsection{Data and Software Maintenance}

Base station management is the responsibility of District staff. This activity includes: initial system setups and configurations; general software maintenance; database maintenance, calibrations and rating table adjustments; alarm settings; interactive hydrologic model support; modem communications, access permissions and security; graphic maps, custom displays and user interfaces; data archiving and database backups; emergency power provisions; and user training [16]. With the District supporting seven base stations, file sharing has become a streamlined process with most changes accomplished quickly by phone modem links. Much time and effort is spent on these tasks.

\subsection{COMPUTER TECHNOLOGIES}

The IBM PC with improved data collection/display software made the task of data archiving more viable, among other things. This particular task also became essential as demands for historic data increased. As the FDN increased in size, the time-consuming task of providing ALERT data to outside users required creative technical solutions. Also, the number of users wanting real-time data access continues to grow steadily.

Driven largely by changes in the computer industry, base stations evolved to meet many of these needs. The current District base station consists of: 1) a 2-node QNX network for primary data collection and display; 2) a stand-alone single node QNX platform dedicated to Internet operations; 3) a Windows NT Workstation serving as a third data collection platform with enhanced graphical displays running an interactive hydrologic model. The NT Workstation is also connected to an NT Server located at the NWS Forecast Office in Boulder for data exchange and integration with their computer systems. This connection also facilitates ongoing research and systems development projects with the NOAA Forecast Systems Laboratory [7]. 


\subsubsection{Software}

The QNX platform runs a proprietary software package marketed by a California-based company, HydroLynx Systems, Inc. The District first began using the QNX operating system [11] in 1985. The current ALERT software evolved from earlier QNX versions, enabling the District to maintain database continuity for the past 15 years. Also, the general look and feel of the menu-driven features has remained consistent, thus limiting the need for user retraining.

The Microsoft Windows-based system (Windows ${ }^{\mathrm{TM}}$ 95/98/NT) uses a software package known as STORM Watch $^{\mathrm{TM}}$. The District's ALERT system maintenance contractor, DIAD Incorporated, is the author of this Microsoft Access ${ }^{\mathrm{TM}}$ driven program. The District began running STORM Watch as part of their ALERT base station operations in 1997, having participated with Boulder County in its initial concept development and testing. This utility provides a very nice visual supplement to the multi-PC District base station environment, among other features.

\subsubsection{Graphical Displays}

Custom reports and graphical displays make interpreting ALERT data much easier. Figure 3 shows one of the most frequently used products available by serial communications and Internet access. The point measurements marked "obs" were added to this figure for discussion later. They represent rainfall amounts reported by individuals from an area not monitored by automated gauges. Graphical maps like this one load very quickly and update automatically as data is received. Remote graphics terminal users can easily change default settings and display tabular reports without exiting the graphics screen. Creating custom tables in a variety of downloadable formats is now relatively simple, enabling users to import ALERT data into their own application software. In the past, features like this were only available to base station terminal operators.

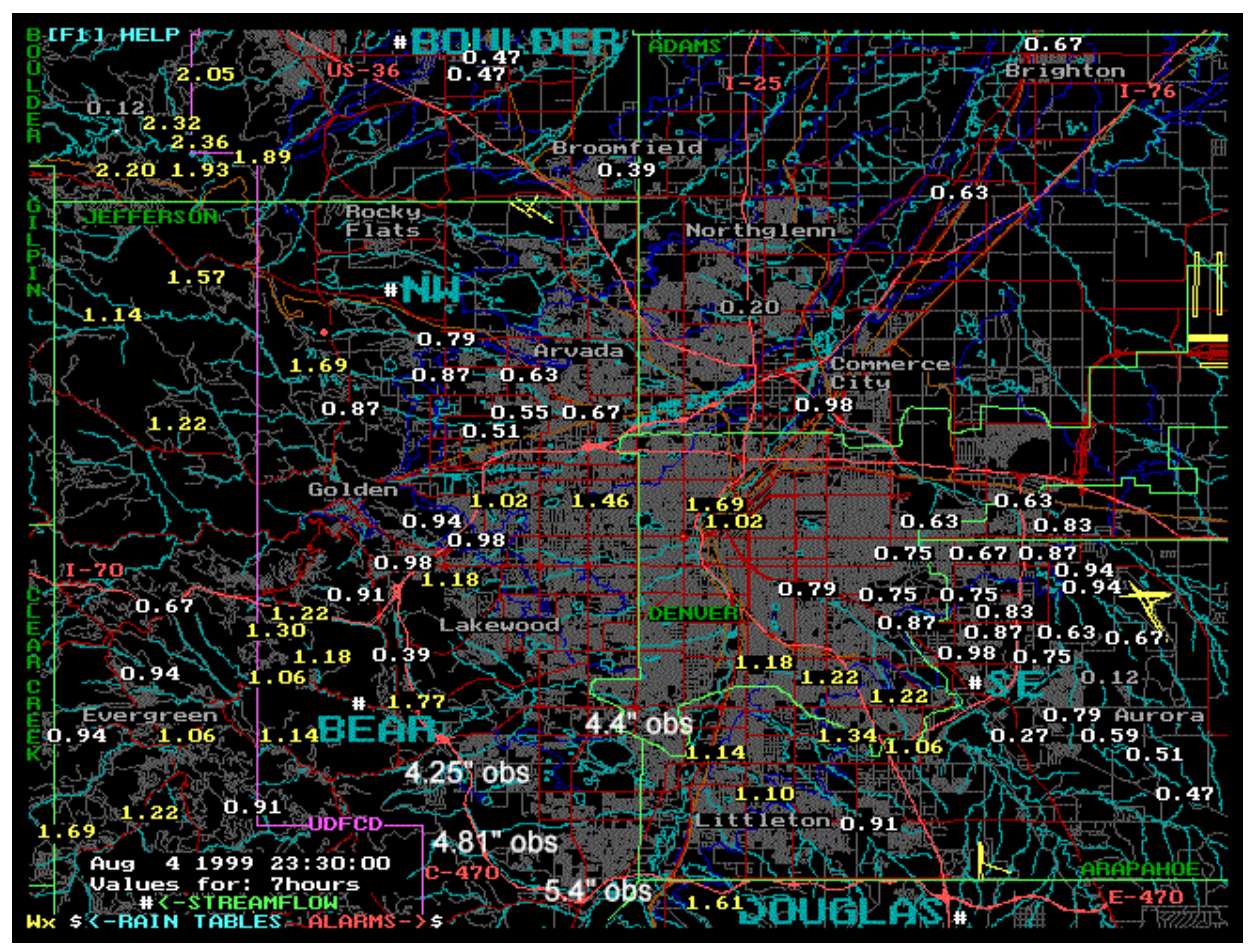

Figure 3. ALERT Rain Map (rainfall totals in inches)

\subsubsection{Remote Access}

Many public safety and public works agencies in the Denver area routinely use the ALERT system for emergency decision-making, and are provided with free dial-up access. External users include the NWS, federal and state water agencies, state and local emergency managers, fire districts, local public works and law enforcement agencies, water departments, private meteorologists and others. Denver television stations use this system to provide their viewers with current rainfall and flood information, and to increase the chance that 
their reporters will be first on the scene for live storm coverage. ALERT data is used during non-flood times for fire weather, stormwater quality monitoring and other alternative applications. Real-time data is also available to the public via the Internet [16].

In addition to ALERT data displays, a full suite of weather products is also available including watches, warnings and advisories from the National Weather Service; and heavy precipitation outlooks, quantitative precipitation forecasts and internal message status reports from the District's F2P2 meteorologist. ALERT data requests and local government interests continue to fuel demands for improved Internet access. Data collection, analysis and display functions have been integrated into an area-wide system operated by the District. Modern graphical displays and telecommunication capabilities have made remote access to this system very popular.

\section{User Groups}

The first large gathering of ALERT users occurred in Monterey, California in 1984. Along with the formation of the ALERT Users Group, committees were established to address technical standards and policy issues confronting local governments. Over the past 15 years the technological advancements in the ALERT industry have been remarkable and the users deserve much credit for many features now widely available. Currently there are three similar user groups in the United States and they are joined by agreement under the auspices of the National Hydrologic Warning Council (Figure 4). This has led to new levels of cooperation with key federal partners and has provided a much larger forum for addressing flood warning issues.

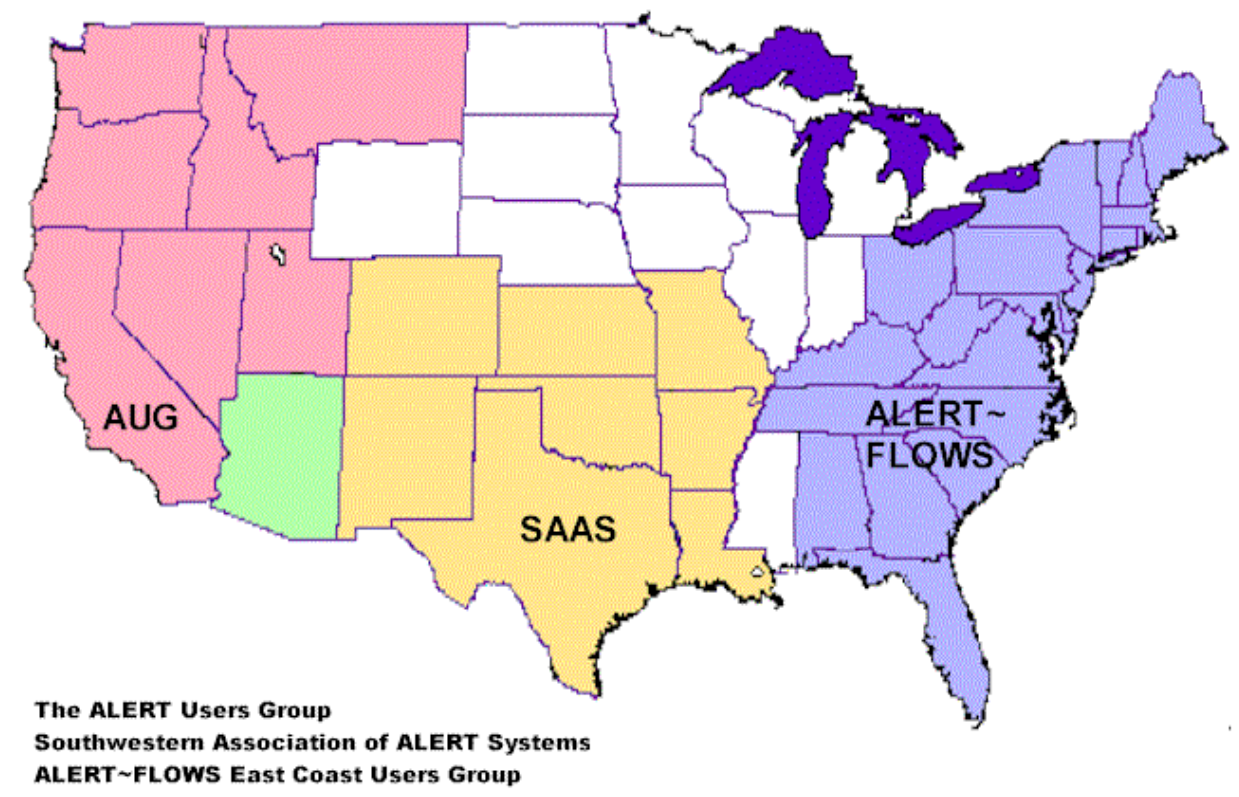

Figure 4. National Hydrologic Warning Council (NHWC) Member User Groups

Initially user groups focused on sharing experiences and ideas through annual conferences and quarterly meetings. ALERT equipment vendors and software developers participated in these events, welcoming suggestions and responding to customer critiques. A technical committee was formed that included vendors in the process of recommending appropriate and feasible technical standards for ALERT. Many design improvements resulted from this process. The committee also studied the pros and cons of using enhanced data transmission formats with error checking. ALERT users continue their work in this area as demands for more efficient use of the radio spectrum were mandated.

Institutional and national policy issues also affect the local flood warning community. Examples include: the modernization and restructuring of the NWS; narrowband legislation affecting government use of radio frequencies; federal training programs for emergency managers; federal funding of local FDNs; flood insurance credits for communities with early warning systems; early warning and detection as an alternative to expensive 
structural dam safety measures; support for the national streamgaging program; scientific investigations of global disaster information networking ideas [9]; and federal efforts to revise hydrologic methods for estimating flood flow frequencies [17]. Through the NHWC, the local flood warning community is frequently asked to participate in these and other activities. Without the user group organizations and the constituencies they represent, such opportunities would not likely have materialized.

\section{Flash Flood Predictions Prompt Proactive Responses}

Early predictions and timely notifications of potential flash flood threats have been the primary objective of the District's local flood warning program from the onset [15]. This hydro-meteorological forecasting component incorporates the use of modern radar, satellite sensing and communications, hydrologic and meteorological models, upper air soundings, real-time surface observations, and other tools. Much insight has been gained in the area of probabilistic quantitative precipitation forecasting (PQPF). As data sources become greater in number, more reliable and easier to interpret, meteorologists continue to improve their ability to recognize the precursors of flash flood producing storms [5,6]. End-user knowledge is also increasing on how to use PQPF and quantitative precipitation estimating (QPE) techniques [10]. Their direct feedback has contributed substantially to the evolution of products and services.

Experience has shown that reliable QPF and corresponding predictions of flood potentials are necessary to prompt early preparedness actions by local officials. In other words, the ALERT system is not relied upon for initial recognition of a flash flood threat and does not constitute an early warning system by itself. The F2P2 meteorologist is responsible for notifying local governments when a developing weather situation may pose a flood threat. Emergency communication centers in each of the six District counties subsequently relay messages to local response agencies using internal fan-out procedures. When warranted, this process activates additional technical support from hydrologists and engineers familiar with local flood problems. It is generally at this point that local officials begin using the ALERT system to monitor rainfall and stream levels, and to interact more frequently with private meteorologists and the NWS. Hence the warning decision process begins in a very proactive way, well before a public warning is needed. In many instances this process has also effectively prevented unnecessary warnings.

The system can be over-stimulated by too many predictions or too much data. This has occurred on occasions. For example, when many weather products are sent by fax to communication centers from more than one source, dispatchers responsible for handling emergency calls may not have the people resources to deal with voluminous amounts of hard copy information. When problems like this occur, the situation is quickly remedied without compromising the primary objective of early notification. Dispatchers continue to receive and disseminate weather information by voice contact, while other local government agencies accept the responsibility of handling hard copy products.

Another type of over-stimulation is when internal alert messages are issued for a number of days consecutively. This is most common during Colorado's monsoon season, typically in late July and early August, when those responsible for monitoring conditions become weary of the seemingly unending "get ready" status. This, however, does not generally result in complaints about F2P2 services but rather, admissions that many are looking forward to the return of good weather. Emergency service agencies want to anticipate problems and be afforded the time to prepare for a proper response, although in doing so they know that many times a field response will not be necessary. Emergency managers have learned to accept and understand the uncertainties associated with making early flash flood predictions.

At this point it is important to clarify the all F2P2 notifications are strictly internal and that the program's meteorologist is not responsible for issuing flash flood warnings to the public. The NWS and local governments have that responsibility. However, it is undeniable that the F2P2 meteorologist does play a key role in prompting their decision to warn the public.

Emphasis continues to be placed on simplifying the evaluation process for recognizing flash flood threats. Through the development of generalized flash flood guidance, real-time hydrologic models, and other sitespecific evaluation techniques, appropriate decision aids have been incorporated in flood warning plans and standard operating procedures. For flash floods in particular, the key meteorological forecast variables are peak rainfall intensity, storm totals, duration, storm size and storm direction/tracking. These parameters are used to predict flood potentials for rivers, streams, reservoirs and other known flood hazards. It should also be noted 
that problem thresholds differ substantially between urban and mountain streams, and that this understanding is reflected in basin-specific flood predictions $[12,13,14]$. The F2P2 meteorologist uses these guidelines to determine the appropriate message to issue and to identify if the forecast represents a low, moderate or high risk to life and property. The generalized flash flood guidance also correlates directly with the PQPF products that predict peak rain intensities for 10,30 and 60-minute durations.

With interests in real-time and archived flood data escalating, the District continues to stress the importance of written plans. The District developed its first basin-specific flood warning plan in 1977. Since then, this concept has been used to develop seven similar plans including the one for Boulder Creek [8] with each plan addressing three fundamental elements: 1) early detection and evaluation of the flood threat, 2) warning dissemination, and 3) response. The local flood warning plans are revised and practiced annually.

\section{Revelations}

Twenty-one years of developing and maintaining local flood warning programs in the Denver area has revealed much. Some revelations were believed true from the beginning, still seem evident today and warrant restating, while others surfaced over time. One thing is certain - the learning process is far from over. The following opinions are offered to help avoid pitfalls as future progress is made through deployment of new technologies, changes in operational procedures and the creation of new programs.

\subsection{ABOUT DISASTERS}

The opening paragraphs of this paper imply that disasters have provided motivation for developing and improving early flood detection technologies, and that they have lead directly to creating new programs, organizations and laws intended to minimize future flood losses. For flash floods in particular, it is the author's opinion that disasters present only narrow windows of opportunity, in some cases very narrow. People tend to address their most urgent needs. When transportation problems are large, solutions are found. When acts of terrorism occur, people demand action and the matter remains a priority for quite some time. When a flash flood disaster occurs, those affected will want to do what they can to prevent it from happening again. But, unlike the transportation problem being a continual nuisance or the terrorist act causing intense lasting emotions, flash floods do not generally happen repetitively to the same area and are considered by many to be "acts of God" beyond human ability to prevent. Consequently, more urgent matters soon take priority and the flood problem can wait, especially since it "probably won't happen for another 100 years." When flood control solutions are proclaimed cost prohibitive, a local flood warning program may be a reasonable and affordable option to consider. Communities should be made aware of this option very soon after a flood and much information is available.

\subsection{ABOUT TECHNOLOGY}

A substantial portion of this paper describes ALERT systems as an effective early flood detection technology available to communities at a reasonable cost. Less discussion is provided concerning the benefits of implementing automated systems like ALERT. It is important to re-emphasize that while ALERT systems and other modern real-time observation technologies are very useful decision-support tools, they are not "flood warning systems" as once advertised by vendors. It is the author's opinion that technology will never replace what people contribute to the process, and that people are the most critical component of a local flood warning system. What technology has clearly done is empower local governments (i.e. people) with the ability to make their own warning decisions with confidence.

Technology does not always let us see everything we would like to see, as illustrated by Figure 3 where observers reported rain amounts that greatly exceeded measurements from nearby ALERT gauges. Radar estimates of rainfall that same day also underestimated what actually occurred. This is not unusual and sometimes it seems that this circumstance is "the rule" rather than the exception. To some degree we will always be limited by technology's inability to point us to the problem that deserves the most attention. On the 
other hand, technology has given its users a new familiarity with specific flood hazards that they may not have gained otherwise.

Mesonet use in the F2P2 has contributed much toward understanding how thunderstorms form and behave [6]. This technology has also lead to increased knowledge by non-technical users. Where meteorological predictions (PQPF and flood forecasts) were once considered by many to be unrealistic "cry wolf" overforecasts, users now look at atmospheric parameters like temperature, dewpoint, wind speed and direction, and note why the forecast "missed" rather than chastise the forecast. Thus, the warning decision process is enhanced by technology in a somewhat surprising and unexpected way, with non-technical people learning first-hand about the uncertainties and difficulties associated with making accurate and timely flood predictions.

\subsubsection{Paybacks}

It is relatively easy to argue that the return on the investment in early flood detection systems will be realized when the next big flood occurs. The problem with this logic is that it may take some time before paybacks are realized, while the recurring maintenance costs may seem too high to justify. For many new system owners, early benefits need to be achieved to sustain interest in and support for these systems.

Fire weather may be the most frequent alternative use of the ALERT system in Denver through an initiative by a local mountain fire district, which made possible a more geographically specific analysis of foothills fire danger. Results are disseminated daily to other agencies involved with fire prevention, mitigation and management.

Water conservation is another alternative use example where the estimated initial paybacks are high. By using real-time rainfall, solar radiation and wind measurements, water users can determine the optimum time to irrigate and precisely how much water to use. One city parks department in the Denver area estimated that this practice saved them $\$ 55,000$ annually. The ALERT system also assists with efforts to improve urban stormwater quality by enhancing capabilities to collect the best possible runoff samples for subsequent analysis [16].

By doing the mathematics for just a few alternative use examples like these, the potential savings and benefits are tremendous. Add to this the paybacks from just one successful flood warning where many lives are saved, and the capital outlay for installing, operating and maintaining one of these systems will seem small.

\subsubsection{Maintenance}

Failing to properly maintain equipment is probably the greatest single reason why some local flood warning programs die early deaths. Long-term commitments to equipment maintenance are essential for achieving positive results, and early exploitation of alternative use benefits may be the best way to accomplish this.

\subsubsection{Communications}

Business is booming in this high-tech era of modern communications. While research and experience instructs us to communicate critical warning information in simple, clear and concise ways-technological advancements suggest that we should never limit our means of delivery. Evolving with technology is the only way we can prevent lagging behind our users' capabilities. Therefore, we should continue to improve our use of: cellular phones, digital pagers and other wireless technologies; the Internet, intranets and email delivery processes; dedicated computer modem links and electronic bulletin boards; multi-point broadcast fax services; urgent voice messaging; area-specific warning dissemination systems like Reverse 911; cable TV interrupts; weather alert radios; media-linked emergency telephone systems; ham radio voice, digital packet and video capabilities; outdoor warning systems; and other developing technologies. As we make use of these tools, we must not overlook the importance of maintaining reliable backup communications for emergency services.

\subsubsection{Partnerships}

The NWS has always been an important flood warning partner. When local governments began acquiring flood detection technologies, this relationship was further enhanced. Technologies like ALERT continue to act as catalysts for forming many new partnerships as well as improving old ones. For example, in Denver the District routinely conducts floodplain tours with local NWS personnel. This popular activity evolved from their initial interest in becoming more familiar with ALERT system and F2P2 operations, and has lead to many other worthwhile cross-training opportunities. 
Partnerships with local television stations have also resulted from their use the ALERT system. Real-time data allows stations to be more effective at sending reporters to obtain live storm and flood coverage. The media also reports ALERT rainfall amounts and stream levels to the public, advising them concerning appropriate safety actions. The District's relationship with the news media has led to interesting behind-the-scenes interactions during events such as dispatching helicopters with live video cameras and reporters to flooded areas.

Many more examples could be given, but the important thing to note is that shared technology will create new partnerships and improve long-standing ones. As with many other aspects of sustaining an effective local flood warning program, lots of maintenance is required in this area as well.

\subsection{ABOUT PREDICTIONS}

Predicting the future of weather will always be uncertain to some degree and the perception people have about weather and flood forecasts will vary widely. Those responsible for preparing weather forecasts and making flash flood predictions should know their target audience and take whatever steps necessary to educate themselves concerning user needs and expectations. Opportunities to provide reciprocal education to users will follow. The F2P2 meteorologist in Denver has the luxury of a very limited target audience comprised primarily of local government officials concerned with public safety. Therefore, products and communications can be tailored specifically for their needs without being too concerned about the general public's need for critical weather information. The NWS, on the other hand, must pay a great deal of attention to how their products and services are perceived by the public.

We must continue to improve our ability to accurately forecast heavy precipitation and quantify the results. The analytical models, data sources and technologies available today give forecasters new ways to present their findings and new understandings about the atmospheric conditions that cause flash floods. The sophistication of users has also changed, allowing technical and non-technical people to converse at much higher levels. Nontechnical users understand probability and can deal with the uncertainties of predicting weather threats. For flash floods in particular, a probabilistic quantitative precipitation forecast (PQPF) should be the first wake-up call for local officials, rather than an alarm from an automated rain or stream gauge.

\subsection{ABOUT PEOPLE}

Behavioral science research of the 1970s appears to have been correct. Developing local flood warning capabilities for Boulder Creek and the rest of the Denver area was a good idea. Local government agencies and other flood warning partners continue to expect timely forecasts and notifications from the $\mathrm{F} 2 \mathrm{P} 2$, and participate actively in the program's evolution and product development. It may now be time to ask this question-will our best efforts at issuing "timely" flash flood warnings be good enough to prevent loss-of-life and minimize property damage when the "big one" happens, given what social scientists know about human behavior? Distinguished colleagues in this field believe that more work is needed before we dare answer "yes" to this question. Specifically, we need to refocus on the business of achieving the desired public response by taking a closer look at our public warning procedures, emergency plans and educational programs.

\subsubsection{Commitment}

Local flood warning programs require commitment from many individuals. Financial resources must be committed from the top (elected officials, governing bodies), but it takes individuals to get the job done. Public agencies, the private sector and volunteer organizations all play roles. While leadership is important, no single agency or individual deserves all the credit. Equipment must be properly maintained; computer systems supported and upgraded; databases calibrated and protected; people trained and educated; warning plans updated and practiced; communication systems and procedures kept current; and decision-support tools enhanced. Government agencies should recognize that the private sector has much to contribute and that their opportunities to provide products and services in a free market society should not be restricted. The task of maintaining high-levels of interest in the program should not be underestimated or taken lightly. 


\subsubsection{Communications}

History suggests that "communications" between people will likely retain its status as the most critical component and the weakest link in early warning/response systems. Of course, one can also argue that without reliable threat detection, critical communications could not be initiated. For the moment let us assume that threat detection works well because essential local commitments have been made. Then we may be able to state that - while technology certainly improves our chances for success, it may come down to what we say and how we say it that ultimately determines whether a flash flood warning is judged effective or ineffective. This truth applies to our inner circle of users (people that make it their business to know) and the public at risk.

Technical personnel must be careful when and how they use technical terms and codes. In certain circumstances total avoidance may be the best policy. By working closely with emergency services, meteorologists and hydrologists can learn how to best communicate weather and flood information, advise concerning the risk, and express urgency when the situation warrants. Warnings issued to the public must also be clear and instructive, but this target audience differs substantially from the public safety community, so much so that we must assume that those in harm's way will not believe that they are in danger. We must also remember that people will seek confirmation of the hazard before warnings are heeded. This warning-related topic is beyond the scope of this paper, but it does help point out why early field mobilization of emergency services is so critical and needs to take place before the flash flood comes. As a final revelation about people and communications, as difficult as it may be, we should make every possible effort to know our audience, maintain good relations, speak their language and keep it simple.

\section{Summary}

Today's computer and data communication technologies have clearly led to a renewed interest in an automated real-time flood detection system that has been serving the public well for 20 years. Local officials responsible for warning decisions in the Denver, Colorado area rely heavily on the high-tech/high-touch forecasting and notification services provided by the Urban Drainage and Flood Control District's flash flood prediction program. Technology used traditionally by hydrologists, meteorologists and engineers (ALERT systems; weather radar; satellite data/images; mesonet data; hydrologic and atmospheric models) is now familiar to the emergency management community, empowering its members to make informed flood warning decisions that will save lives and minimize property damage.

The Internet, high-speed data communications, creative graphics software, and modern computers are credited with the increasing worldwide popularity of ALERT and other early flood detection systems. Alternative uses of ALERT data have resulted in many public benefits that were not anticipated 20 years ago. The paybacks have been tremendous, but the most notable byproduct of this technology may be the many worthwhile partnerships that have evolved. People are important and like high-tech equipment, good relationships require maintenance. It is the author's hope that the discussions, thoughts and opinions shared in this paper will prove useful to many other communities threatened by flash floods, and provide a foundation to further improve the District's local flood warning and early notification program for the Denver/Boulder metropolitan area.

\section{References}

1. Burnash, R.J.C. (1996) ALERT - a real-time data system for hydrologic warnings, ALERT Transmission, AUG-SAAS newsletter, winter 1996 issue.

2. Downing, T.E. (1977) Warning for flash floods in Boulder, Colorado, Natural Hazard Research Working Paper 31, Institute of Behavioral Science, University of Colorado, Boulder, CO, 80pp.

3. Downing, T.E. (1977) Flash Flood Warning Recommendations for Front Range Communities, Urban Drainage and Flood Control District, Denver, CO, 25pp.

4. Gruntfest, E.C. (1977) What people did during the Big Thompson flood, Natural Hazard Research Working Paper 32, Institute of Behavioral Science, University of Colorado, Boulder, CO, 62pp. 
5. Henz Kelly and Associates (1989) UDFCD flash flood prediction program quantitative precipitation forecasting mass curve product evaluation, Urban Drainage and Flood Control District, Denver, CO, 18pp.

6. Henz, J.F. (1993) Operationally predictable updraft characteristics of heavy precipitation producing thunderstorms, Proceedings of the 16th Conference on Severe Local Storms, American Meteorological Society, 847-849.

7. Jesuroga, R.T., C. Subramaniam and P.A. Miller (1998) The AWIPS local data acquisition and dissemination system, National Oceanic and Atmospheric Administration, Forecast Systems Laboratory, Boulder, CO, Paper FA 8.16.

8. Leonard Rice Consulting Water Engineers, Inc. (1977) Early Flood Warning Planning for Boulder Creek, Urban Drainage and Flood Control District, Denver, CO.

9. National Research Council; Commission on Geosciences, Environment and Resources; Board on Natural Disasters (1999) Reducing losses through better information. National Academy Press, National Academy of Sciences, Washington, D.C.

10. National Weather Service, National Oceanic and Atmospheric Administration, U.S. Department of Commerce (1999) The Modernized End-to-End Forecast Process for Quantitative Precipitation Information: Hydrometeorological Requirements, Scientific Issues and Service Concepts, Silver Spring, MD.

11. QNX Software Systems Ltd. (1993) QNX 4 Operating System User's Guide, Kanata, Ontario, Canada.

12. Sabol, G. and J.F. Henz (1990) Simplified mountain canyon flash flood guidance for Boulder Creek, Urban Drainage and Flood Control District, Denver, CO, 13pp.

13. Stewart, K.G. (1987) Planning for the inevitable - urban flash flood warning systems in the Denver metropolitan area, Realistic Approaches to Better Floodplain Management, Special Publication \#18, Natural Hazards Research and Applications Information Center, Boulder, CO, 206-211.

14. Stewart, K.G. (1988) Effecting timely responses to urban flash floods, Computerized Decision Support for Water Managers, Proceedings of the 3rd water resources operations management workshop, American Society of Civil Engineers, New York, NY, 759771.

15. Stewart, K.G. (1997) Flood warning systems and early notification procedures in Denver, Colorado, Flood Warnings: Issues and Practice in Total System Design, ISBN No: 185924128 X, Flood Hazard Research Centre, Middlesex University, UK, $105-113$.

16. Stewart, K.G. (1999) Managing and distributing real-time and archived hydrologic data for the Urban Drainage and Flood Control District's ALERT system, Compact disk proceedings of the 26th annual water resources planning and management conference, American Society of Civil Engineers, New York, NY.

17. United States Water Resources Council (1977) Guidelines for Determining Flood Flow Frequency, Bulletin 17A of the Hydrology Committee, U.S. Government Printing Office: 1976-622-018, Washington, D.C. 